\title{
Dental anomalies in orthodontic patients with and without skeletal discrepancies
}

\author{
Clarissa Christina Avelar Fernandez ${ }^{1}$, Mônica Gentil Mattos ${ }^{1}$, Christiane Vasconcellos Cruz Alves Pereira ${ }^{1}$, Marcelo de Castro Costa ${ }^{1}$ \\ ${ }^{1}$ Department of Pediatric Dentistry and Orthodontics, Federal University of Rio de Janeiro, Rio de Janeiro, Brazil
}

\section{Abstract}

Objective: To determine whether individuals with skeletal discrepancies of Class II or III display a higher frequency of dental anomalies in comparison with individuals with Class I malocclusion.

Design: A systematic search of the main electronic medical scientific literature databases was conducted. Observational studies were selected if mentioning dental anomalies in the different skeletal malocclusion patterns.

Results: A total of 4,768 studies were found and the duplicated studies $(1,279)$ were removed, resulting in 3,489 papers to be analyzed. After screening by title, 138 were fit for screening by abstract. After that, a total of 13 papers were carefully read in full. Five studies included dental anomaly frequencies in orthodontic patients and included 7,679 participants. The frequency of dental anomalies ranged from $11.2 \%$ to $40.3 \%$. It was observed that individuals with skeletal discrepancies of Class II and III had more dental anomalies when compared to individuals with Class I. Conclusion: Individuals with skeletal malocclusion patterns have more dental anomalies and there is an association between dental anomalies and skeletal Class II or Class III malocclusion patterns.
Citation: Fernandez CCA, et al. (2020) Dental anomalies in orthodontic patients with and without skeletal discrepancies. Dentistry 3000. 1:a001 doi:10.5195/d3000.2020.96

Received: March 30, 2020

Accepted: April 5, 2020

Published: April 15, 2020

Copyright: (C2020 Fernandez CCA, et al. This is an open access article licensed under a Creative Commons Attribution Work 4.0 United States License.

Email: pttpo2009@yahoo.com.br

\section{Introduction}

Dental anomalies are clinical alterations resulting from disturbances during the tooth formation process. ${ }^{1}$ They represent disturbances of number, size, shape, position and structure of the teeth. ${ }^{1,2}$ The prevalence of dental anomalies can range from 5.46 to $74.7 \%$, 1,3 due to different ethnicities and diagnostic criteria. ${ }^{1,4,5}$ The etiology of dental anomalies includes genetic and environmental factors. ${ }^{2,5,6}$
Skeletal malocclusions are usually categorized and described by disturbances in the craniofacial and occlusal relationships ${ }^{7}$ and often appear together with the dental anomalies, asserting their relation and complicating therapy. ${ }^{8} \mathrm{It}$ appears that dental anomalies may be more likely to occur if individuals have Class II or Class III relationships in comparison to Class $1 .{ }^{9}$ This sophisticated clinical definition is a base for phenotype-genotype correlation, that may contribute to more accurate treatment predictions and to genetic studies. ${ }^{9}$ This systematic review aimed to confirm that evidence exists that individuals with Class I skeletal malocclusion are less likely to have dental anomalies.

\section{Material and Methods}

The present systematic review was registered at Prospective Register of Systematic Reviews (PROSPERO; Centre for Reviews and Dissemination, University of York; and the National Institute for Health Research) under the registry number 
CRD42016038916 and followed the Preferred Reporting Items for Systematic Review and Meta Analyses (PRISMA) checklist. ${ }^{10}$

\section{Search Strategy}

The following focused question was formulated: "Is there a difference in the frequency of dental anomalies in orthodontic patients with Class II or III versus Class I malocclusion?" To develop the focused question, a set of criteria for study eligibility was adopted, based on PECOS strategy (Population: orthodontic patients; Exposure: skeletal discrepancies; Comparator: standard of normality; and Outcome: dental anomalies), using $\mathrm{MeSH}$, entry terms and key words (Table 1).

The main search was conducted in November 2016 and was updated on January 2019. Publications of potential relevance to this study were identified after searching the main electronic medical scientific literature databases, including PubMed, Scopus, LILACS, Web of Science, the Cochrane Library, and Google Scholar. Additional articles of potential relevance were identified by manual searches. Textbooks, dissertations, case reports, case series, review articles, and abstracts were excluded. Studies

Table 1. PECOS strategy (Population; Exposure; Comparator; and Outcome), using $\mathrm{MeSH}$, entry terms and key words

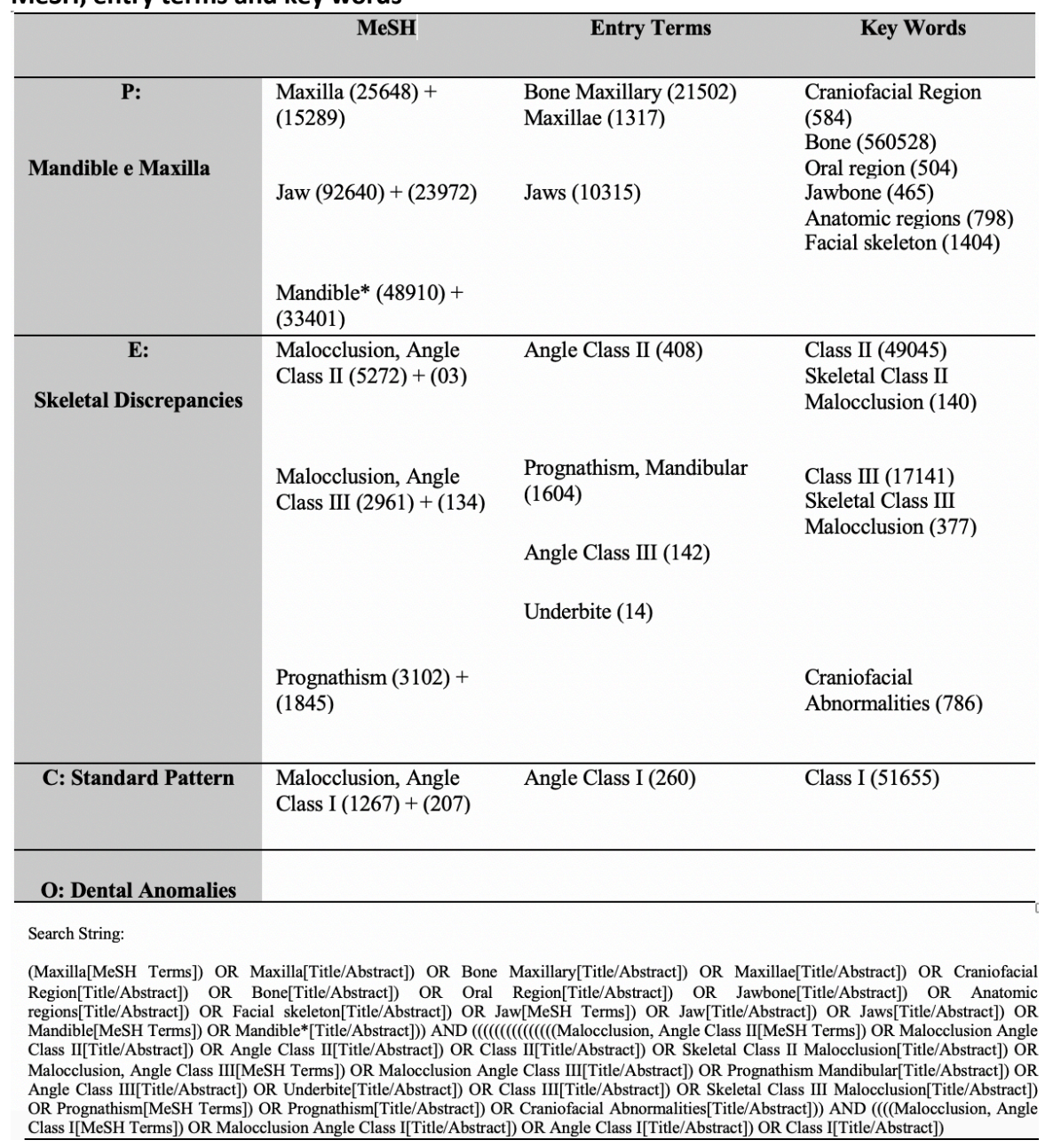

in populations presenting specific systemic diseases, conditions (history of trauma, cleft lip and/or palate, syndromes), endocrine imbalances and/or metabolic disorders (being these sporadic or hereditary), and no descriptions of the three skeletal malocclusions were excluded.

Two examiners (C.C.A.F. and M.G.M.) independently screened each paper by examining the title, abstract, and keywords. No restriction was applied regarding language or date of publication.

The selected studies were described in relation to the type of study, total sample, sex distribution, how the diagnosis of skeletal malocclusion and dental anomalies were performed, and the frequency of dental anomalies in each malocclusion. Dental anomalies were also grouped in anomalies of number, shape and position (Table $\mathbf{2}$ ).

\section{Results and Discussion}

Observational studies were included because they mentioned dental anomalies in the different skeletal malocclusion patterns, enabling comparison between groups (Classe I, II and III) and different populations. Figure 1 shows the flow diagram of the search results from the databases. After search, a total of 4,768 records were found: 750 from Cochrane Library, 1,616 from PubMed, 911 from Scopus, 323 from Scopus-Med, 1,158 from Web of Science, four from LILACS and BBO, and six from Google Scholar. 
Table 2. Data extracted from the five selected studies.

\begin{tabular}{|c|c|c|c|c|c|c|}
\hline $\begin{array}{l}\text { Type of } \\
\text { study }\end{array}$ & Sample & $\begin{array}{l}\text { Males } \\
\text { N (\%) }\end{array}$ & $\begin{array}{c}\text { Females } \\
\text { N (\%) }\end{array}$ & $\begin{array}{c}\text { Skeletal } \\
\text { malocclusion } \\
\text { diagnosis } \\
\text { method }\end{array}$ & $\begin{array}{l}\text { Dental anomalies } \\
\text { diagnosis method }\end{array}$ & $\begin{array}{c}\begin{array}{c}\text { Prevalence of } \\
\text { dental }\end{array} \\
\text { anomalies } \\
\mathbf{N}(\%)\end{array}$ \\
\hline $\begin{array}{l}\text { Chung et } \\
\text { al., } 2008\end{array}$ & 1793 & $611(37.7)$ & $1011(62.3)$ & $\begin{array}{l}\text { cephalometric } \\
\text { tracing }\end{array}$ & $\begin{array}{c}\text { Panoramic } \\
\text { radiographs, and } \\
\text { dental models }\end{array}$ & $182(11.2)$ \\
\hline $\begin{array}{l}\text { Uslu et } \\
\text { al., } 2009\end{array}$ & 900 & $352(39.1)$ & $548(60.9)$ & $\begin{array}{l}\text { cephalometric } \\
\text { tracing }\end{array}$ & $\begin{array}{l}\text { Panoramic/periapical } \\
\text { radiographs, photos, } \\
\text { records and dental } \\
\text { models }\end{array}$ & $363(40.3)$ \\
\hline Observational & 3055 & $1205(39.5)$ & $1850(60.5)$ & not reported & $\begin{array}{l}\text { Panoramic and } \\
\text { periapical } \\
\text { radiographs, and } \\
\text { dental models }\end{array}$ & $344(11.3)$ \\
\hline $\begin{array}{l}\text { Celicoglu } \\
\text { and } \\
\text { Kamak, } \\
2012\end{array}$ & 146 & $449(42.9)$ & $597(57.1)$ & $\begin{array}{l}\text { cephalometric } \\
\text { tracing }\end{array}$ & $\begin{array}{l}\text { Panoramic } \\
\text { radiographs and } \\
\text { records }\end{array}$ & $237(22.7)$ \\
\hline $\begin{array}{l}\text { Fernandez Observational } \\
\text { et al., } \\
2018\end{array}$ & 1047 & $453(43.3)$ & $594(56.7)$ & $\begin{array}{l}\text { cephalometric } \\
\text { tracing }\end{array}$ & $\begin{array}{c}\text { Panoramic and } \\
\text { periapical } \\
\text { radiographs, photos, } \\
\text { records and dental } \\
\text { models }\end{array}$ & $127(15.7)$ \\
\hline Studies & $\begin{array}{c}\text { Class I-no } \\
\text { dental } \\
\text { anomalies } \\
\text { (N) } \\
\end{array}$ & $\begin{array}{c}\text { Class II - no } \\
\text { dental } \\
\text { anomalies } \\
\text { (N) } \\
\end{array}$ & $\begin{array}{l}\text { Class III - } \\
\text { no dental } \\
\text { anomalies } \\
\text { (N) }\end{array}$ & $\begin{array}{c}\text { Class I- with } \\
\text { dental } \\
\text { anomalies (N) }\end{array}$ & $\begin{array}{l}\text { Class II-with } \\
\text { dental anomalies } \\
\text { (N) }\end{array}$ & $\begin{array}{l}\text { Class III - } \\
\text { with dental } \\
\text { anomalies } \\
\text { (N) }\end{array}$ \\
\hline Chung et al., 2008 & 979 & 256 & 376 & 103 & 19 & 60 \\
\hline Uslu et al., 2009 & 202 & 221 & 99 & 156 & 155 & 67 \\
\hline Young, 2010 & 862 & 985 & 864 & 123 & 117 & 104 \\
\hline Celicoglu and Kamak, 2012 & 290 & 290 & 229 & 74 & 72 & 91 \\
\hline Fernandez et al., 2018 & 158 & 136 & 28 & 152 & 113 & 43 \\
\hline Studies & $\begin{array}{c}\text { Class I- } \\
\text { with dental } \\
\text { anomalies of } \\
\text { number (N) }\end{array}$ & $\begin{array}{c}\text { Class II- } \\
\text { with dental } \\
\text { anomalies of } \\
\text { number (N) }\end{array}$ & $\begin{array}{c}\text { Class III - } \\
\text { with dental } \\
\text { anomalies } \\
\text { or number } \\
(\mathbf{N}) \\
\end{array}$ & $\begin{array}{c}\text { Class I - with } \\
\text { dental } \\
\text { anomalies of } \\
\text { shape }(\mathbf{N})\end{array}$ & $\begin{array}{c}\text { Class II - with } \\
\text { dental anomalies of } \\
\text { shape (N) }\end{array}$ & $\begin{array}{c}\text { Class III - } \\
\text { with dental } \\
\text { anomalies of } \\
\text { shape }(\mathrm{N})\end{array}$ \\
\hline Chung et al., 2008 & 103 & 19 & 60 & $\cdots$ & $\cdots$ & + \\
\hline Uslu et al., 2009 & 83 & 73 & 41 & 163 & 73 & 31 \\
\hline Young, 2010 & 123 & 117 & 104 & 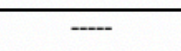 & +- & + \\
\hline Celicoglu and Kamak, 2012 & 72 & 74 & 91 & +- & 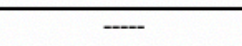 & ב-- \\
\hline Fernandez et al., 2018 & 58 & 38 & 13 & 21 & 15 & 12 \\
\hline Studies & $\begin{array}{c}\text { Class I- } \\
\text { with dental } \\
\text { anomalies of } \\
\text { position (N) }\end{array}$ & $\begin{array}{c}\text { Class II- } \\
\text { with dental } \\
\text { anomalies of } \\
\text { position (N) }\end{array}$ & $\begin{array}{c}\text { Class III- } \\
\text { with dental } \\
\text { anomalies } \\
\text { of position } \\
(\mathrm{N}) \\
\end{array}$ & & Study conclusion & \\
\hline Chung et al., 2008 & --- & $-\overline{---}$ & --- & \multicolumn{3}{|c|}{$\begin{array}{l}\text { Hypodontia was associated with third molar agenesis and } \\
\text { skeletal Class III malocclusion. }\end{array}$} \\
\hline Uslu et al., 2009 & 17 & 6 & 8 & \multicolumn{3}{|c|}{$\begin{array}{l}\text { A remarkably high rate of dental anomalies was recorded } \\
\text { in orthodontic patients. }\end{array}$} \\
\hline Young, 2010 & --- & +-- & ---- & \multicolumn{3}{|c|}{$\begin{array}{l}\text { The prevalence of hypodontia in Koreans is relatively } \\
\text { high. }\end{array}$} \\
\hline Celicoglu and Kamak, 2012 & ---- & $\overline{-\cdots--}$ & ---- & \multicolumn{3}{|c|}{$\begin{array}{l}\text { Third molar agenesis depends on sagital|skeletal } \\
\text { malocclusions. }\end{array}$} \\
\hline Fernandez et al., 2018 & 73 & 60 & 18 & \multicolumn{3}{|c|}{$\begin{array}{l}\text { Microdontia was associated with the skeletal Class III } \\
\text { malocclusion pattern, and tooth agenesis was associated } \\
\text { with the hypodivergent growth pattern. }\end{array}$} \\
\hline
\end{tabular}


Figure 1. Flow diagram of the literature search and selection process implemented.

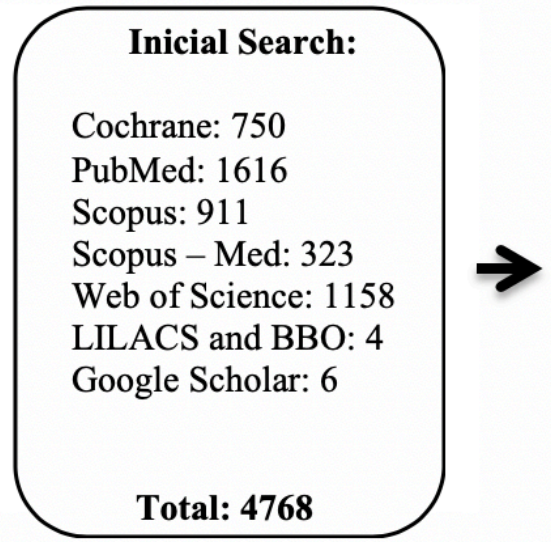

The duplicated studies $(1,279)$ were removed, resulting in 3,489 records to be analyzed. After screening by title, 138 were fit for screening by abstract. After that, a total of 13 records were carefully read in full and five studies containing 7,679 participants were selected. The eight studies were excluded because they did not have the classification of skeletal malocclusions patterns.

Table 2 shows the extraction of the data from the selected studies. The frequency of dental anomalies ranged from $11.2 \%$ to $40.3 \% .^{1,9,11,12,13}$ It was observed that individuals with skeletal discrepancies (Class II and III) had more dental anomalies when compared to individuals with no skeletal discrepancies (Class I). ${ }^{1,9,12,13}$ The same was observed for dental anomalies of number, ${ }^{1,12,13}$ shape, and position. ${ }^{10}$ Three studies only made the diagnosis of tooth agenesis ${ }^{11,13}$ and/or third molar agenesis. ${ }^{11,12}$

The studies included in this systematic review had a frequency of dental anomalies raging from
After removal of duplicates:

Cochrane: 749

PubMed: 1559

Scopus: 492

Scopus - Med: 6

Web of Science: 673

LILACS and BBO: 4

Google Scholar: 6

Total: 3489
$11.2 \%$ to $40.3 \%$. Celicoglu and Kamak $(2012)^{12}$ reported a frequency of $22.7 \%$ of dental anomalies whereas Fernandez et al. $(2018)^{9}$ reported a frequency of $15.7 \%$ of dental anomalies of number, shape and position. Uslu et al. (2009) ${ }^{1}$ had the highest frequency of dental anomalies among orthodontic patients of the five studies selected $(40.3 \%)$, having tooth agenesis, evagination, and invagination as the most common dental anomalies. The studies that found the lowest frequency of dental anomalies in orthodontic patients were of Young (2010) and Chung et al. (2008), ${ }^{11}$ with a frequency of $11.3 \%$ and $11.2 \%$, respectively. It is likely that these differences are due to the different populations studied (Turkish, Brazilian, and Korean) and different dental anomaly definitions.

\section{Conclusion}

In summary, individuals with skeletal Class II or Class III malocclusion patterns have more dental anomalies than individuals who are Class I. In addition, there is an association between dental anomalies and skeletal Class II or Class III malocclusion patterns.

\section{Acknowledgments}

This work was developed as part of a course on systematic reviews and meta-analysis taken by C.C.A.F. and M.G.M. We thank Lucianne Cople Maia, Marcela Baraúna Magno, and Danielle Masterson for this learning experience.

\section{References}

1. Prevalence of dental anomalies in various malocclusions. Uslu O, Akcam MO, Evirgen S, Cebeci I. Am J Orthod Dentofacial Orthop. 2009 Mar;135(3):328-35. doi: 10.1016/j.ajodo.2007.03.030.

2. The Class II Division 2 craniofacial type is associated with numerous congenital tooth anomalies. Basdra EK, Kiokpasoglou M, StelIzig A. Eur J Orthod. 2000 Oct;22(5):529-35.

3. [Agenesis in permanent dentition]. Diaz-Perez R, Echaverry-Navarrete RA. 
Rev Salud Publica (Bogota). 2009

Dec;11(6):961-9.

4. Prevalence and distribution of dental anomalies in orthodontic patients. Altug-Atac AT, Erdem D. Am J Orthod Dentofacial Orthop. 2007 Apr;131(4):510-4.

5. Investigation of hypodontia as clinically relates dental anomaly: Prevalence and characteristics. Kim YH. ISRN Dentistry 2011;Article ID 246135, 6 pages.

6. Studies of dental anomalies in a large group of school children.

Küchler EC, Risso PA, Costa Mde C, Modesto A, Vieira AR. Arch Oral Biol. 2008 Oct;53(10):941-6. doi: 10.1016/j.archoralbio.2008.04.00.

7. Congenital tooth anomalies and malocclusions: a genetic link? Basdra EK, Kiokpasoglou MN, Komposch G. Eur J Orthod. 2001 Apr;23(2):145-51.

8. Prevalence of Dental Anomalies among School Going Children in India. Kathariya MD, Nikam AP, Chopra K, Patil NN, Raheja H, Kathariya R. J Int Oral Health. 2013 Oct;5(5):10-4.

9. Dental anomalies in different growth and skeletal malocclusion patterns. Fernandez CCA, Pereira CVCA, Luiz RR, Vieira AR, De Castro Costa M. Angle Orthod. 2018 Mar;88(2):195-201. doi: 10.2319/071917-482.1.

10. Preferred reporting items for systematic reviews and meta- analyses: the PRISMA statement. Moher D, Liberati A, Tetzlaff J, Altman DG; PRISMA Group. Int J Surg. 2010;8(5):336-41. doi: 10.1016/j.ijsu.2010.02.007.

11. The pattern and prevalence of hypodontia in Koreans. Chung $\mathrm{CJ}$, Han JH, Kim KH. Oral Dis. 2008 Oct;14(7):620-5. doi: 10.1111/j.16010825.2007.01434.x.

12. Patterns of third-molar agenesis in an orthodontic patient population with different skeletal malocclusions. Celikoglu M, Kamak H. Angle Orthod. 2012 Jan;82(1):1659. doi: 10.2319/041911-274.1. 